\title{
WORKPLACE BULLYING AND MENTAL HEALTH AMONG TEACHERS IN RELATION TO PSYCHOSOCIAL JOB CHARACTERISTICS AND BURNOUT
}

\author{
LINA BERNOTAITE ${ }^{1}$ and VILIJA MALINAUSKIENE ${ }^{1,2,3}$ \\ ${ }^{1}$ Lithuanian University of Health Sciences, Kaunas, Lithuania \\ Department of Population Studies, Institute of Cardiology \\ ${ }^{2}$ Lithuanian University of Health Sciences, Kaunas, Lithuania \\ Department of Environmental and Occupational Medicine \\ ${ }^{3}$ Lithuanian Sports University, Kaunas, Lithuania \\ Department of Health, Physical and Social Education
}

\begin{abstract}
Objectives: The objective of the study has been to assess the associations between psychological distress and exposure to workplace bullying, taking into account possible influence of adverse psychosocial job characteristics and occupational burnout in a sample of Kaunas (Lithuania) teachers. Material and Methods: The study sample included 517 teachers from 13 secondary schools and was conducted in 2014. The participants filled in the anonymous questionnaire (response rate $71.3 \%$ ). Twenty-two-item Negative Acts Questionnaire (H. Hoel and S. Einarsen) was used for measuring the exposure to workplace bullying, Goldberg 12-item General Health Questionnaire (GHQ-12) - psychological distress, Maslach Burnout Inventory (MBI) - occupational burnout, Karasek Demand-Control questionnaire - psychosocial job stressors. The IBM SPSS Statistics version 20.0 was used for performing the statistical analysis. Associations between psychological distress, exposure to workplace bullying, psychosocial job characteristics and occupational burnout were analyzed in the logistic regression and expressed in terms of odds ratios (OR). Statistical significance was determined using the $95 \%$ confidence interval (CI) level. Results: Workplace bullying was prevalent among Kaunas teachers (occasional $-8.3 \%$, severe $-2.9 \%$ ). Twenty-five percent of teachers suffered from psychological distress. High emotional exhaustion was found in $25.6 \%$ of them, high depersonalization in $10.6 \%$ and low personal achievement in $33.7 \%$ of cases. Almost a half of respondents $(47.4 \%)$ reported job strain and 59.6\% - low social support at work. Occasional and severe bullying was associated with psychological distress after adjusting to job strain, social support and emotional exhaustion, depersonalization, personal accomplishment (adjusted OR was 3.27, 95\% CI: 1.56-6.84 for occasional and 4.98, 95\% CI: 1.27-19.62 for severe bullying). Conclusions: Occasional and severe bullying were strong predictors for psychological distress. Burnout did not mediate those associations. The effect of job strain and low social support decreased to the insignificant level in the final model. Preventive measures are necessary to improve psychosocial working conditions in secondary education institutions. Int J Occup Med Environ Health 2017;30(4):629-640
\end{abstract}

Key words:

Teachers, Psychosocial job characteristics, Psychological distress, Workplace bullying, Occupational epidemiology,

Occupational burnout

Received: February 26, 2016. Accepted: June 28, 2016.

Corresponding author: L. Bernotaite, Lithuanian University of Health Sciences, Department of Population Studies, Institute of Cardiology, Sukileliu av. 15, Kaunas LT-50161, Lithuania (e-mail: Ibernotaite@alumni.unav.es). 


\section{INTRODUCTION}

Numerous investigations conducted within recent years in the field of mental health support the conception of mental health as an integral and essential component of health. The definition of mental health provided by the World Health Organization (WHO) describes it as a state of wellbeing in which an individual realizes his or her own potential, may cope with the normal stresses of life, can work productively and fruitfully, and is able to make a contribution to her or his community [1]. The WHO also affirms that mental health problems result from a compound of interacting psychological, biological, social and environmental factors and that there is an increasing evidence that both - the content and the context of work may play a role in the development of mental health problems in the workplace [2]. The investigations reveal that employment in occupations related to human services, such as health care, social work and educational system, suggests the association with psychological distress [3]. The results of a number of studies assent that schoolteachers fall into the category of professionals who may experience a huge amount of work-related stress, which may lead to sustained physical and mental health problems, and that one of the co-worker groups most affected by psychological problems namely include teachers [4-7].

The Lithuanian educational system undergoes the organizational reforms on a continuous basis, which results in numerous changes in the daily work, hence extra workload and work related stress to be absorbed by its employees. Due to the aforementioned organizational changes and insufficient financial reward, the dissatisfaction with working conditions at schools is often escalated by labor unions in mass media, however, the specific mental health hazards the teachers face are rarely publicized.

The results of earlier studies affirm that a stressful work environment often leads to a workplace bullying due to worsened interpersonal relationships caused by strained working conditions [8]. The research of workplace bul- lying started in the early 1980's, and since then various investigators have used different terms, such as mobbing, hostile behavior or psychological abuse to describe this phenomenon [9]. In 2011 Einarsen et al. provided a comprehensive definition of workplace bullying describing it as harassing, offending or socially excluding someone or negatively affecting someone's work behavior, that occurs repeatedly and regularly, e.g., weekly and lasts for a period of time, e.g., about 6 months [10]. According to the results of the fifth European Working Conditions Survey, carried out in 2011-2012, education sector is one of those, which tends to have the highest levels of incidence of workplace bullying [11]. The Polish investigators conducted a study among teachers, which suggested that experience of hostile behavior and bullying at work was significantly associated with symptoms of occupational burnout [12]. Other researchers propose that in the public view as well as amongst teachers, burnout is commonly regarded as an innate problem of this particular profession [13].

Burnout that consists of 3 dimensions - emotional exhaustion, depersonalization and reduced professional efficacy [14] - is a widespread health-related problem in the current working life and develops as a prolonged response to chronic emotional and interpersonal stressors that repeatedly occur in the working environment [15]. It is most common in the case of occupations with close social interactions and it is confirmed that teachers have the highest burnout levels as compared to other professionals in social services [16]. The results of a number of studies have confirmed that high job demands result in the occupation burnout which, in turn, leads to health problems in various occupational groups, including teachers [17]. Several longitudinal epidemiological studies affirm that adverse psychosocial job characteristics, namely - high job demands, low job control and low social support at work - constitute one of the risks for poor mental health [18]. In our previous study among family physicians in Lithuania we showed that workplace bullying was a substantial risk factor for 
poor mental health far exceeding the risk associated with other work and everyday life stressors. The study results indicated the cumulative effects of exposure to several stressors, including workplace bullying and psychosocial job characteristics (high demands, low control, and low social support at work) that contributed to the victimization and development of mental health problems [19]. Recent investigations were directed towards the understanding of possible interconnections between bullying and burnout, showing that bullying was positively associated with burnout among nurses [20,21]. Another recent study on nurses has indicated that workplace bullying does not affect health directly, but only indirectly, via mediation of burnout [22].

In this study, we have tried to reveal how bullying is associated with psychological distress among teachers, what effect of job strain, low social support at work, life threatening events is and how burnout is interconnected in the pathway between workplace bullying and poor mental health. Thus, we have aimed to assess the association between exposure to workplace bullying and psychological distress among Kaunas (Lithuania) teachers taking into account the possible influence of other psychosocial workrelated stressors (job strain, low social support at work), occupational burnout and threatening life events happening outside the workplace.

\section{MATERIAL AND METHODS}

\section{Participants and procedure}

The study sample consisted of 517 teachers from Kaunas (Lithuania) secondary schools $(\mathrm{N}=3)$, gymnasiums $(\mathrm{N}=7)$ and pro-gymnasiums $(\mathrm{N}=3)$. For the purpose of participation in the research, the schools were selected based on the localization in order to represent various districts of the city. The participating institutions represented 8 out of 11 city neighborhoods. The collection of data started upon receipt of approbation of the Chief of the Kaunas City Municipality Education Department, as well as the approval of the Regional Biomedical Research Ethics Committee and was processed in the year of 2014. The researchers visited participating schools during the routine staff meetings, explained the purpose of the research to the employees and confirmed the unmitigated confidentiality and anonymity of the collected data. Every teacher who attended the staff meeting was provided with the Subject Information and Informed Consent Form and the anonymous self-administrative questionnaire for completion purposes. The participation in the study was voluntary. Teachers who agreed to take part in the research were asked to sign the Informed Consent Form and to return the filled in questionnaires by placing them into the sealed boxes within 5 working days from receipt.

According to the Lithuania Official Statistics Portal, 3023 teachers were employed in Kaunas City secondary education institutions in 2014-2015. Out of 725 distributed questionnaires, 517 (response rate $-71.3 \%$ ) were returned. The mean age of participants was 49.92 years old (standard deviation $(\mathrm{SD})=9.11$ ). Four hundred and nineteen $(81 \%)$ were female and $41(7.9 \%)$ were male. Fifty-seven $(11 \%)$ respondents did not indicate their gender, $42(8.12 \%)$ did not indicate their age.

\section{Instruments}

Participants completed the anonymous self-administered questionnaire which included sociodemographic measures - age, gender, marital status (having a partner or spouse, divorced, single, widow(er)), a number of children living at home, work and family interference evaluated with a single question with the answers on a 7-point scale and globally used questionnaires, translated and validated for usage in Lithuania to measure psychological distress, psychosocial job characteristics and occupational burnout.

The 22-item Negative Acts Questionnaire (H. Hoel and S. Einarsen) was used for assessing the variety of negative behavior forms from colleagues, superiors and students; 
however, the collected data was not analyzed in this paper work. Victimization from workplace bullying was measured using the single-item measure. The respondents were asked to indicate whether or not they had been exposed to bullying during the previous 6 months based on the provided definition of bullying: "A situation where one or several individuals persistently over a period of time perceived oneself to be on the receiving end of negative actions from one or several persons, in a situation where the target of the bullying has difficulty in defending him/ herself against these actions. A one-off incident is not bullying." The response categories were: "No," "Yes, very rarely," "Yes, now and then," "Yes, several times per week" and "Yes, almost daily." Victimization from workplace bullying was then classified into occasional ("Yes, very rarely") and severe ("Yes, now and then," "Yes, several times per week" and "Yes, almost daily") [23].

Psychological distress was measured by Goldberg 12item General Health Questionnaire (GHQ-12) which is a well-established scale for the evaluation of psychological distress in population samples, valued for its excellent screening performances and good clinical validity in terms of diagnosing mental disorders [3] and used in a number of the WHO studies and in the primary care sector [24]. The short GHQ version consists of 12 questions, covering feelings of strain, anxiety-based insomnia, depression, inability to cope, lack of self-confidence and other symptoms of psychological distress. Three and more positive answers were assessed as psychological distress. Cronbach's $\alpha$ in this sample was 0.751 .

The risk for occupational burnout was measured using the widely applied Maslach Burnout Inventory (MBI) [25]. It is a 22-item questionnaire divided into 3 subscales: emotional exhaustion, 9 items (the feelings of being emotionally overrun and exhausted by one's work); depersonalization, 5 items (the tendency to view others as objects rather than as feeling persons), and personal achievement, 8 items (the degree to which a person perceives doing well on worthwhile tasks). The items are answered in terms of the frequency with which the respondent experiences those feelings, on a 7-point scale ranging from 0 (never) to 6 (every day). The 3 dimensions are measured for each respondent. A higher score indicates greater burnout except for personal accomplishment that is rated inversely and low scores indicate high burnout. Specifically, a high degree of burnout is represented by high scores of emotional exhaustion (low: $\leq 13$, medium: 14-26, high: $\geq 27$ ), high scores of depersonalization (low: $\leq 5$, medium: 6-9, high: $\geq 10$ ), and low scores of personal accomplishment (low: $\leq 33$, medium: 34-39, high: $\geq 40$ ). Cross-cultural adaptation of the Inventory has been described previously [26]. Cronbach's $\alpha$ in that sample was 0.871 for emotional exhaustion, 0.748 for depersonalization and 0.837 for personal achievement.

The Swedish version of the Karasek Demand-Control questionnaire was used for measuring psychosocial job stressors. The questionnaire, that was previously adapted in Lithuanian and used in the previous research, consists of 6 items for the assessment of job control, 5 items for evaluation of psychological demands and 6 items for assessment of supervisor and co-worker support [27]. Each question had 4 response categories for frequency ranging from "never" to "always." The scoring was directed in such a way that high score meant greater demand, more decision latitude and higher levels of social support. Job strain was calculated as the ratio of demands to control. Cronbach's $\alpha$ in that sample was 0.706 .

The respondents were also queried about the occurrence of life-threatening events such as divorce, death or fatal disease of a family member and financial crisis within the past 12 months.

IBM SPSS Statistics version 20.0 was used for performing the statistical analysis. Firstly, prevalence data for psychological distress by independent variables was calculated and chi-squared tests were used with p-values. Pearson correlations were calculated between continuous measures of workplace bullying and burnout dimensions. Secondly, 
associations between the psychological distress and exposure to workplace bullying, adverse psychosocial job characteristics, risk to occupational burnout components - emotional exhaustion, depersonalization and personal achievement and threatening life events were analyzed in the logistic regression and expressed in terms of odds ratios (OR) and its $95 \%$ confidence interval (CI) level. Statistical significance was determined if $p<0.05$. Adjustments for sociodemographic factors were made in all analyses.

Four models were estimated:

- The associations between workplace bullying and psychological distress were adjusted to demographical factors: marital status, a number of children in the family as well as work and family interference.

- To test the hypothesis that psychosocial job characteristics and threatening life events might affect the associations between workplace bullying and psychological distress, further adjustment to job strain, social support at work and threatening life events was performed in model II.

- In model III the possible mediating effect of burnout dimensions together with life threatening events was tested.

- In model IV all above mentioned variables were included in one model to test if elevated OR for workplace bullying would be effected.

\section{RESULTS}

According to the GHQ-12 assessment results, a quarter $(25 \%)$ of all respondents was classified as sufferers from psychological distress. High emotional exhaustion was found in $25.6 \%$, high depersonalization in $10.6 \%$ and low personal achievement in $33.7 \%$ of cases. Almost a half of respondents (47.4\%) reported job strain and 59.6\% low social support at work.

The Table 1 presents the distribution of sociodemographic and psychosocial work factors in the groups of sufferers and non-sufferers from psychological distress. The study results revealed that psychological distress among women was more frequent than among men $(p<0.0001)$. However, the frequency of psychological distress between the age groups was not significant $(p>0.05)$. The prevalence of occasional bullying among questioned Kaunas teachers was $8.3 \%$, severe bullying $-2.9 \%$. Teachers with psychological distress were exposed more often to occasional and severe bullying and witnessed bullying as compared to teachers not suffering from psychological distress. Bullying from the superiors was reported by $6.6 \%$ of teachers, from colleagues $-3.7 \%$, meanwhile bullying rate from students was the highest $-11.4 \%$. Bullying was witnessed by $3.3 \%$ of respondents. The research results demonstrate that bullying by students and colleagues and frequent witnessing of negative behavior is more related to the development of mental distress than bullying by superiors. And teachers with psychological distress more often experience job strain, low social support at work, emotional exhaustion, depersonalization and low personal achievement. Pearson correlation between workplace bullying and emotional exhaustion was $0.165(\mathrm{p}<0.01)$ and depersonalization $-0.260(\mathrm{p}<0.01)$. To gain more knowledge of the complex links between psychological distress and bullying, the logistic regression analysis was applied allowing the influence of other independent variables.

The Table 2 presents logistic regression models which evaluate the associations between psychological distress (dependent variable) and independent variables used in this study - bullying, psychosocial job characteristics, burnout dimensions and threatening life events.

Firstly we assessed the association between workplace bullying and psychological distress after adjustment to marital status, a number of children in the family and work-family interference. In model I occasional as well as severe bullying was strongly associated with psychological distress with the OR equal to 5. After adjustment to job strain and social support at work the adjusted $\mathrm{OR}\left(\mathrm{OR}_{\text {adj }}\right)$ decreased to 3 , but in model III the values of odds ratios for severe 
Table 1. Workplace bullying, psychosocial job characteristics, burnout and threatening life events among teachers with and without psychological distress symptoms

\begin{tabular}{|c|c|c|c|c|c|}
\hline \multirow{3}{*}{ Variable } & \multicolumn{4}{|c|}{ Respondents } & \multirow{3}{*}{$\mathrm{p}$} \\
\hline & \multicolumn{2}{|c|}{$\begin{array}{c}\text { with } \\
\text { psychological distress } \\
(\mathrm{N}=129)\end{array}$} & \multicolumn{2}{|c|}{$\begin{array}{c}\text { without } \\
\text { psychological distress } \\
(\mathrm{N}=388)\end{array}$} & \\
\hline & $\mathrm{n}$ & $\%$ & $\mathrm{n}$ & $\%$ & \\
\hline Gender & & & & & $<0.0001$ \\
\hline men & 1 & 0.9 & 40 & 11.6 & \\
\hline women & 115 & 99.1 & 304 & 88.4 & \\
\hline Age & & & & & 0.227 \\
\hline 24-34 years & 4 & 3.4 & 23 & 6.5 & \\
\hline $35-44$ years & 28 & 23.5 & 94 & 26.5 & \\
\hline 45-54 years & 54 & 45.4 & 127 & 35.8 & \\
\hline$\geq 55$ years & 33 & 27.7 & 111 & 31.3 & \\
\hline Workplace bullying & & & & & $<0.0001$ \\
\hline no & 96 & 74.4 & 363 & 93.6 & \\
\hline occasional & 24 & 18.6 & 19 & 4.9 & \\
\hline severe & 9 & 7.0 & 6 & 1.5 & \\
\hline Bully students & & & & & $<0.0001$ \\
\hline no & 99 & 76.7 & 359 & 92.5 & \\
\hline yes & 30 & 23.3 & 29 & 7.5 & \\
\hline Bully superiors & & & & & 0.149 \\
\hline no & 117 & 90.7 & 366 & 94.3 & \\
\hline yes & 12 & 9.3 & 22 & 5.7 & \\
\hline Bully colleagues & & & & & 0.004 \\
\hline no & 379 & 97.7 & 119 & 92.2 & \\
\hline yes & 9 & 2.3 & 10 & 7.8 & \\
\hline Bullying witness & & & & & $<0.0001$ \\
\hline no & 88 & 68.2 & 332 & 85.6 & \\
\hline rarely & 31 & 24.0 & 49 & 12.6 & \\
\hline frequently & 10 & 7.8 & 7 & 1.8 & \\
\hline Job strain & & & & & $<0.0001$ \\
\hline low & 41 & 31.8 & 231 & 59.5 & \\
\hline high & 88 & 68.2 & 157 & 40.5 & \\
\hline Social support & & & & & $<0.0001$ \\
\hline high & 27 & 20.9 & 182 & 46.9 & \\
\hline low & 102 & 79.1 & 206 & 53.1 & \\
\hline Emotional exhaustion & & & & & $<0.0001$ \\
\hline low & 18 & 14.3 & 144 & 38.4 & \\
\hline moderate & 29 & 23.0 & 135 & 36.0 & \\
\hline high & 79 & 62.7 & 96 & 25.6 & \\
\hline
\end{tabular}


Table 1. Workplace bullying, psychosocial job characteristics, burnout and threatening life events among teachers with and without psychological distress symptoms - cont.

\begin{tabular}{|c|c|c|c|c|c|}
\hline \multirow{3}{*}{ Variable } & \multicolumn{4}{|c|}{ Respondents } & \multirow{3}{*}{$\mathrm{p}$} \\
\hline & \multicolumn{2}{|c|}{$\begin{array}{c}\text { with } \\
\text { psychological distress } \\
(\mathrm{N}=129)\end{array}$} & \multicolumn{2}{|c|}{$\begin{array}{c}\text { without } \\
\text { psychological distress } \\
(\mathrm{N}=388)\end{array}$} & \\
\hline & $\mathrm{n}$ & $\%$ & $\mathrm{n}$ & $\%$ & \\
\hline Depersonalization & & & & & $<0.0001$ \\
\hline low & 50 & 39.7 & 253 & 67.7 & \\
\hline moderate & 44 & 34.9 & 100 & 26.7 & \\
\hline high & 32 & 25.4 & 21 & 5.6 & \\
\hline Personal achievement & & & & & $<0.0001$ \\
\hline high & 27 & 21.4 & 188 & 50.0 & \\
\hline moderate & 32 & 25.4 & 86 & 22.9 & \\
\hline low & 67 & 53.2 & 102 & 27.1 & \\
\hline Threatening life events & & & & & 0.028 \\
\hline yes & 85 & 65.9 & 294 & 75.8 & \\
\hline no & 44 & 34.1 & 94 & 24.2 & \\
\hline
\end{tabular}

Table 2. Associations between psychological distress and workplace bullying, psychosocial job characteristics, burnout and threatening life events among teachers in the logistic regression models*

\begin{tabular}{|c|c|c|c|c|c|c|c|c|}
\hline \multirow{2}{*}{ Variable } & \multicolumn{2}{|c|}{ Model I } & \multicolumn{2}{|c|}{ Model II } & \multicolumn{2}{|c|}{ Model III } & \multicolumn{2}{|c|}{ Model IV } \\
\hline & $\mathrm{OR}_{\mathrm{adj}}$ & $95 \% \mathrm{CI}$ & $\mathrm{OR}_{\text {adj }}$ & $95 \% \mathrm{CI}$ & $\mathrm{OR}_{\mathrm{adj}}$ & $95 \% \mathrm{CI}$ & $\mathrm{OR}_{\mathrm{adj}}$ & $95 \% \mathrm{CI}$ \\
\hline No bullying (reference) & - & - & - & - & - & - & - & - \\
\hline occasional & 5.05 & $2.60-9.83$ & 3.61 & $1.82-7.17$ & 3.74 & $1.79-7.82$ & 3.27 & $1.56-6.84$ \\
\hline severe & 5.05 & $1.60-16.02$ & 3.34 & $1.02-10.99$ & 6.18 & $1.58-24.08$ & 4.98 & $1.27-19.62$ \\
\hline job strain & & & 2.02 & $1.27-3.22$ & & & 1.37 & $0.82-2.29$ \\
\hline low social support & & & 2.19 & $1.31-3.65$ & & & 1.72 & $0.99-3.01$ \\
\hline Low emotional exhaustion (reference) & & & & & - & - & - & - \\
\hline moderate & & & & & 1.47 & $0.74-2.94$ & 1.47 & $0.73-2.96$ \\
\hline high & & & & & 4.70 & $2.34-9.44$ & 4.15 & $2.04-8.43$ \\
\hline Low depersonalization (reference) & & & & & & & & \\
\hline moderate & & & & & 1.25 & $0.72-2.17$ & 1.22 & $0.70-2.12$ \\
\hline high & & & & & 2.07 & $0.95-4.51$ & 1.89 & $0.86-4.15$ \\
\hline High personal achievement (reference) & & & & & - & - & - & - \\
\hline moderate & & & & & 2.49 & $1.30-4.75$ & 2.38 & $1.23-4.59$ \\
\hline low & & & & & 4.27 & $2.34-7.80$ & 3.89 & $2.12-7.16$ \\
\hline Threatening life events & & & 1.34 & $0.83-2.16$ & 1.34 & $0.79-2.26$ & 1.31 & $0.77-2.21$ \\
\hline
\end{tabular}

* Model I adjusted to marital status, work-family interference, a number of children in the family; model II adjusted to marital status, work-family interference, a number of children in the family, job strain, social support and threatening life events; model III adjusted to marital status, workfamily interference, a number of children in the family, emotional exhaustion, depersonalization, personal achievement and threatening life events; model IV adjusted to marital status, work-family interference, a number of children in the family, job strain, social support, emotional exhaustion, depersonalization, personal achievement and threatening life events.

$\mathrm{OR}_{\text {adj }}$ - adjusted odds ratio; CI - confidence interval. 
bullying increased to 6.18. In the final model that included both - psychosocial job characteristics and burnout dimensions, odds ratios for occasional bullying and severe bullying remained significant and were 3.27 (95\% CI: 1.566.84) and 4.98 (95\% CI: 1.27-19.62), respectively. The effect for job strain and social support at work lost the statistical significance in the final model. Model III and Model IV results revealed that teachers with high emotional exhaustion were approximately 4-times more often likely to have psychological distress than the ones with low emotional exhaustion. Personal achievement was also associated with psychological distress in the final model.

Threatening life events were found to be not significant in all the models $(p>0.05)$.

\section{DISCUSSION}

The aim of this study has been to investigate the association between exposure to workplace bullying and psychological distress in Kaunas (Lithuania) teachers taking into account the possible influence of other psychosocial workrelated stressors, burnout and threatening life events. To our best knowledge, this is the first study on the relationship between bullying and psychological distress in the sample of Kaunas teachers that has also included and investigated the links to adverse psychosocial job characteristics and occupational burnout.

The research results revealed that the prevalence of psychological distress was $25 \%$ as assessed using the self-reported GHQ-12 questionnaire. Very similar results were provided by German researchers, namely mental distress was reported by $29.8 \%$ of teachers using the same GHQ12 instrument [24]. Study results in other countries show comparable scores [28]. The rate of psychological distress found among Japanese teachers is higher - 62.9\% [29]. In our study we have found women to experience psychological distress significantly more often than men $-27.4 \%$ vs. $2.4 \%$ ( $p<0.0001)$. The results provided by other researchers indicate the gender proportion to be more balanced - $14 \%$ among females and 15\% - among males as found by Ofili et al. [28], 47.8\% - among males and $57.8 \%$ - among females as reported by Japanese investigators [30] or $31.5 \%$ vs. $28 \%$ among German teachers [24]. A significant increase in psychological distress with age among teachers was observed by Kovess-Mastefy et al. [31]. We, however, did not find significant difference in mental distress prevalence between different age groups ( $p>0.05)$. We found that almost $1 / 3(29.8 \%)$ of respondents aged 45-54 years suffered from mental distress.

The prevalence of occasional bullying was $8.3 \%$ and severe bullying $-2.9 \%$. A very similar score of severe bullying among Kaunas teachers (2.6\%) was reported by Lithuanian researchers back in 2005, meanwhile the prevalence of occasional bullying was almost 3-fold higher - 23\% [32]. According to the Fifth European Working Conditions Survey results, the prevalence of bullying in general population varies across the European Union (EU) Member States from approximately $0.6 \%$ in Bulgaria to $9.5 \%$ in France [11] and this difference could be explained by cultural differences and the level of awareness of the phenomenon in separate countries. The recent study in Spanish and Italian samples found the bullying prevalence to be at the rate of $15 \%$ [33]. The results of the study carried out among Polish teachers suggested the prevalence of bullying at the rate of $7 \%$ [12]. Our results indicated that job strain and low social support were associated with psychological distress in model II (OR for job strain was 2.02, 95\% CI: $1.27-$ 3.23, OR for low social support was $2.19,95 \%$ CI: $1.31-$ 3.65). Those results were consistent with other research outcomes [34,35] and corresponded to the job strain model. Though in the final model the OR for job strain and low social support decreased to the statistically insignificant level. Other researchers also indicated that cumulative exposure to a high strain job was not associated with poorer outcomes in adjusted models [36].

We have found that $34.9 \%$ of surveyed teachers suffer from high emotional exhaustion and our results 
comply with the rates of burnout that range between $25 \%$ and $35 \%$ in many European countries [37]. In model III adjusted to burnout dimensions, high emotional exhaustion increases the risk for mental distress by almost 5 -fold $\left(\mathrm{OR}_{\mathrm{adj}}=4.70,95 \%\right.$ CI: $\left.2.34-9.44\right)$ and remains a similarly strong predictor in the final model with OR $=4.15,95 \%$ CI: $2.04-8.43$. While the causes of burnout are complex, some studies have linked the experience of workplace violence with higher rates of burnout $[12,20,21,38]$, but the interdependence of bullying with burnout on mental health is sometimes controversial.

In our study, we have tested the comprehensive model of concomitant effect of psychosocial job characteristics and burnout in the associations of workplace bullying and psychological distress among teachers. We have found that workplace bullying is associated with the distress in all the adjusted models. The effect of severe bullying remains stable with the OR $=4.98,95 \%$ CI: $1.27-19.62$, therefore indicating the cumulative effects of all investigated variables. Other studies have also shown that experiences and outcomes of workplace bullying may be hidden within other health-related problems at work or in one's daily life or behavioral and personality characteristics $[19,39,40]$. In our study burnout has not mediated the associations between workplace bullying and psychological distress, but it has mediated the effect of job strain as well as in the study of teachers conducted in Poland [17]. Our study has demonstrated that sources of burnout among teachers might be other than bullying and may reflect organizational climate as well as personality characteristics.

To summarize, this study has shown that occasional and severe bullying remains to be strong predictors for psychological distress in all the models, including the final one adjusted to adverse psychosocial work characteristics and burnout dimensions. Burnout has not mediated the associations between workplace bullying and psychological distress, high emotional exhaustion and low personal accomplishment have shown strong independent effect in the associations with poor mental health. The results have also shown that threatening life events lose the statistical significance in all the models ( $p>0.05$ ). The aforementioned results confirm the importance to improve psychosocial working conditions in the secondary education institutions by reducing bullying exposure and promoting employee health and well-being through established nationwide strategies or local school policies.

\section{Strengths and limitations}

The strengths of the study were that our sample size was relatively large to produce reliable results. Three thousand and twenty-three teachers were employed in Kaunas secondary education institutions in 2014-2015 according to the Lithuania Official Statistics Portal. We surveyed nearly 1/5 (approximately 17.1\%) of the employees of Kaunas educational system. Moreover our study covered 8 out of 11 city neighborhoods, which reduced the possibility of differences in socio-cultural context. Since Kaunas is the second largest city in Lithuania and the educational system is uniform across the country, we can estimate that similar data would be collected in other regions. Yet, the comparative studies in other regions, including rural areas are necessary in order to draw more generalized conclusions with respect to teachers nationwide. We have also used reliable and valid instruments for measuring study variables.

Another strength of our study was the fact that we investigated the concomitant effect of many predictors on poor mental health and showed that burnout and workplace bullying were independently associated with psychological distress.

Nevertheless, we should also admit and mention several limitations of this research. Firstly, due to a cross-sectional design of the study we should be cautious while interpreting the results as we can only describe correlations but not prove the causal relationships between the variables. Hence, longitudinal studies should be conducted to gain more knowledge 
about the causality of the relationships between psychological distress, workplace bullying, psychosocial job characteristics and occupational burnout. Secondly, the collected data in the used questionnaire is based on self-reports, which raises the possibility of reporting bias. Furthermore, it is also worth noting that victimization from workplace bullying was measured using the single-item measure, leaving it up to a respondent to define the concept of bullying.

\section{CONCLUSIONS}

The workplace bullying was prevalent at the rates of $8.3 \%$ for occasional and $2.9 \%$ for severe bullying. A quarter $(25 \%)$ of Kaunas teachers suffered from psychological distress. Our study revealed that occasional and severe bulling were strong predictors for psychological distress after adjustment to adverse psychosocial job characteristics and burnout. Burnout did not mediate those associations. Workplace bullying and burnout were independently associated with poor mental health among teachers. Since adverse psychosocial working conditions lead teachers to poorer mental health, which in turn affects educational process of new generations, preventive measures, such as nationwide strategies or local school policies should be applied to reduce bullying, to improve psychosocial working conditions in secondary education institutions and to promote employee health and well-being.

\section{ACKNOWLEDGMENTS}

Technician Mindaugas Malinauskas created the data set and statistician Egle Sepetauskiene provided help in the statistical analysis. Departmental Chair Abdonas Tamosiunas provided general support.

\section{REFERENCES}

1. World Health Organization [Internet]. Geneva: The Organization; 2001 [updated 2014 Aug; cited 2016 Jan 15]. Mental health: Strengthening our response. Fact Sheet No. 220. Available from: http://www.who.int/mediacentre/factsheets/fs220/en/.
2. World Health Organization. Mental health policies and programmes in the workplace (Mental Health Policy and Service Guidance Package) [Internet]. Geneva: The Organization; 2005 [cited 2016 Jan 15]. Available from: http:// www.who.int/mental_health/policy/services/13_policies $\% 20$ programs $\% 20$ in $\% 20$ workplace_WEB_07.pdf.

3. Malinauskiene V, Leisyte P, Malinauskas R. Psychosocial job characteristics, social support, and sense of coherence as determinants of mental health among nurses. Medicina (Kaunas); 2009;45(11):910-7.

4. Elder Ch, Nidich S, Moriarti F, Nidich R. Effect of transcendental meditation on employee stress, depression, and burnout: A randomized controlled study. Perm J. 2014; 18(1):19-23, https://doi.org/10.7812/TPP/13-102.

5. Naghieh A, Montgomery P, Bonell CP, Thompson M, Aber JL. Organizational interventions for improving wellbeing and reducing work-related stress in teachers. Cochrane Database Syst Rev. 2015;4:CD010306, https://doi. org/10.1002/14651858.CD010306.pub2.

6. Wang Y, Ramos A, Wu H, Liu L, Yang X, Wang J, et al. Relationship between occupational stress and burnout among Chinese teachers: A cross-sectional survey in Liaoning, China. Int Arch Occup Environ Health. 2015;88(5):589-97, https://doi.org/10.1007/s00420-014-0987-9.

7. Franco C, Mañas I, Cangas AJ, Moreno E, Gallego J. Reducing teachers' psychological distress through a mindfulness training program. Span J Psychol. 2010;13(2):655-66, https://doi.org/10.1017/S1138741600002328.

8. Takaki J, Taniguchi T, Fukuoka E, Fujii Y, Tsutsumi A, Nakajima K, et al. Workplace bullying could play important roles in the relationships between job strain and symptoms of depression and sleep disturbance. J Occup Health. 2010;52(6):367-74, https://doi.org/10.1539/joh.L10081.

9. Astrauskaite M, Perminas A, Kern RM. Sickness, colleagues' harassment in teachers' work and emotional exhaustion. Medicina (Kaunas). 2010;46(9):628-34.

10. Salin D. Risk factors of workplace bullying for men and women: The role of the psychosocial and physical work 
environment. Scand J Psych. 2015;56:69-77, https://doi. org/10.1111/sjop.12169.

11. Eurofound. Physical and psychological violence at the workplace [Internet]. Luxembourg: Publications Office of the European Union; 2013 [cited 2016 Jan 15]. Available from: https://doi.org/10.2806/49169.

12. Mościcka-Teske A, Drabek M, Pyżalski J. [Experienced bullying and hostile behavior in the workplace and symptoms of burnout in teachers]. Med Pr. 2014;65(4):535-42, https://doi. org $/ 10.13075 / \mathrm{mp} .5893 .00017$. Polish.

13. Hillert A, Koch S, Lehr D. [Burnout phenomenon exemplified by the teaching profession: Paradigms, findings and perspectives of profession-related therapy and prevention approaches]. Nervenarzt. 2013;84(7):806-12, https://doi. org/10.1007/s00115-013-3745-4. German.

14. Martinez E, Mera G, González C, López DM, Blobel B. EmoBurnout: An approach for supporting burnout syndrome diagnosis. Stud Health Technol Inform. 2015;211: 111-8, https://doi.org/10.3233/978-1-61499-516-6-111.

15. Helkavaara M, Saastamoinen PM, Lahelma E. Psychosocial work environment and emotional exhaustion among middle-aged employees. BMC Res Notes. 2011;4:101, https:// doi.org/10.1186/1756-0500-4-101.

16. Mojsa-Kaja J, Golonka K, Marek T. Job burnout and engagement among teachers - Worklife areas and personality traits as predictors of relationships with work. Int J Occup Med Environ Health. 2015;28(1):102-19, https://doi. org/10.13075/ijomeh.1896.00238.

17. Baka $\measuredangle$. Does job burnout mediate negative effects of job demands on mental and physical health in a group of teachers? Testing the energetic process of Job Demands-Resources model. Int J Occup Med Environ Health. 2015;28(2): 335-46, https://doi.org/10.13075/ijomeh.1896.00246.

18. Choi BK, Ostergren PO, Canivet C, Moghadassi M, Lindeberg S, Karasek R, et al. Synergistic interaction effect between job control and social support in at work on general psychological distress. Int Arch Occup Environ Health. 2011;84:77-89, https://doi.org/10.1007/s00420-010-0554-y.
19. Malinauskiene V, Einarsen S. Workplace bullying and posttraumatic stress symptoms among family physicians in Lithuania: An occupation and region specific approach. Int J Occup Med Environ Health. 2014;27(6):919-32, https://doi. org/10.2478/s13382-014-0328-y.

20. Allen BC, Holland P, Reynolds R. The effect of bullying on burnout in nurses: the moderating role of psychological detachment. J Adv Nurs. 2015;71(2):381-90, https://doi. org/10.1111/jan.12489.

21. Laschinger HK, Grau AL, Finegan J, Wilk P. New graduate nurses' experiences of bullying and burnout in hospital settings. J Adv Nurs. 2010;66(12):2732-42, https://doi. org/10.1111/j.1365-2648.2010.05420.x.

22. Giorgi G, Mancuso S, Fiz Perez F, Castiello D’Antonio A, Mucci N, Cupelli V, et al. Bullying among nurses and its relationship with burnout and organizational climate. Int J Nurs Pract. 2016;22(2):160-8, https://doi.org/10.1111/ ijn.12376.

23. Einarsen S, Hoel H, Notelaers G. Measuring exposure to bullying and harassment at work: Validity, factor structure and psychometric properties of the Negative Acts Questionnaire-Revised. Work Stress. 2009;23(1):24-44, https://doi. org/10.1080/02678370902815673.

24. Bauer J, Unterbrink T, Hack A. Working conditions, adverse events and mental health problems in a sample of 949 German teachers. Int Arch Occup Environ Health. 2007;80: 442-9, https://doi.org/10.1007/s00420-007-0170-7.

25. Schaufeli WB, Bakker AB, Hoogduin K, Schaap C, Kladler A. On the clinical validity of the Maslach Burnout Inventory and the Burnout Measure. Psychol Health. 2001;16(5): 565-82, https://doi.org/10.1080/08870440108405527.

26. Mikalauskas A, Širvinskas E, Marchertienè I, Macas A, Samalavičius R, Kinduris Š, et al. Burnout among Lithuanian cardiac surgeons and cardiac anesthesiologists. Medicina (Kaunas). 2012;48(9):478-84.

27. Malinauskiene V, Theorell T, Grazuleviciene R, Azaraviciene A, Obelenis V, Azelis V. Psychosocial factors at work and myocardial infarction among men in Kaunas, Lithuania. 
Scand J Work Environ Health. 2005;31(3):218-23, https:// doi.org/10.5271/sjweh.872.

28. Ofili AN, Usiholo EA, Oronsaye MO. Psychological morbidity, job satisfaction and intentions to quit among teachers in private secondary schools in Edo-State, Nigeria. Ann Afr Med. 2009;8(1):32-7, https://doi.org/10.4103/15963519.55761 .

29. Nagai M, Tsuchiya KJ, Toulopoulou T, Takei N. Poor mental health associated with job dissatisfaction among school teachers in Japan. J Occup Health. 2007;49:515-22, https:// doi.org/10.1539/joh.49.515.

30. Bannai A, Ukawa S, Tamakoshi A. Long working hours and psychological distress among school teachers in Japan. J Occup Health. 2015;57:20-7, https://doi.org/10.1539/joh. 14-0127-OA.

31. Kovess-Mastefy V, Sevilla-Dedieu C, Rios-Seidel C, Nerriere E, Chan Chee C. Do teachers have more health problems? Results from a French cross-sectional survey. BMC Public Health. 2006;6:101, https://doi.org/10.1186/1471-2458-6-101.

32. Malinauskienė V, Obelenis V, Šopagienè D. Psychological terror at work and cardiovascular diseases among teachers. Acta Med Litu. 2005;12:20-5.

33. Arenas A, Giorgi G, Montani F, Mancuso S, Perez JF, Mucci N, et al. Workplace bullying in a sample of Italian and Spanish employees and its relationship with job satisfaction, and psychological well-being. Front Psychol. 2015;15(6):1912, https://doi.org/10.3389/fpsyg.2015.01912.

34. Theorell T, Hammarström A, Gustafsson PE, Magnusson Hanson L, Janlert U, Westerlund H. Job strain and depressive symptoms in men and women: A prospective study of the working population in Sweden. J Epidemiol Community
Health. 2014;68(1):78-82, https://doi.org/10.1136/jech-2012202294.

35. Stenfors CU, Magnusson Hanson L, Oxenstierna G, Theorell T, Nilsson LG. Psychosocial working conditions and cognitive complaints among Swedish employees. PLoS One. 2013;8(4):e60637, https://doi.org/10.1371/journal.pone. 0060637.

36. Burns RA, Butterworth P, Anstey KJ. An examination of the long-term impact of job strain on mental health and wellbeing over a 12-year period. Soc Psychiatry Psychiatr Epidemiol. 2016;51(5):725-33, https://doi.org/10.1007/s00127-016-1192-9.

37. Bauer J, Stamm A, Virnich K, Wissing K, Muller U, Wirshing $\mathrm{M}$, et al. Correlation between burnout syndrome and psychological and psychosomatic symptoms among teachers. Int Arch Occup Environ Health. 2006;79:199-204, https:// doi.org/10.1007/s00420-005-0050-y.

38. Zafar W, Khan UR, Siddiqui SA, Jamali S, Razzak JA. Workplace violence and self-reported psychological health: Coping with post-traumatic stress, mental distress, and burnout among physicians working in the emergency departments compared to other specialties in Pakistan. J Emerg Med. 2016;50(1):167-77, https://doi.org/10.1016/ j.jemermed.2015.02.049.

39. Trépanier SG, Fernet C, Austin S. A longitudinal investigation of workplace bullying, basic need satisfaction, and employee functioning. J Occup Health Psychol. 2015;20(1): 105-16, https://doi.org/10.1037/a0037726.

40. Poraj G. Psychological models of female teachers' functioning in their professional role. Int J Occup Med Environ Health. 2010;23(1):33-46, https://doi.org/10.2478/v10001010-0007-6.

This work is available in Open Access model and licensed under a Creative Commons Attribution-NonCommercial 3.0 Poland License - http://creativecommons.org/ licenses/by-nc/3.0/pl/deed.en. 